\title{
PESQUISAR E PESQUISAR-SE NA EDUCAÇÃO: MOVIMENTOS CRIADOS PELA ESTÉTICA E PELAS SENSIBILIDADES
}

\author{
RESEARCH AND RESEARCH IN EDUCATION: \\ MOVEMENTS CREATED BY AESTHETICS AND SENSITIVITIES
}

Silvia Sell Duarte Pillotto

Doutora em Engenharia de Produção (Gestão da Qualidade), Universidade Federal de Santa Catarina (UFSC) Florianópolis, SC - Brasil pillotto0@gmail.com

Carla Clauber da Silva Universidade do Estado de Campinas (UNICAMP) Campinas, SP - Brasil carlaclauber@hotmail.com

\begin{abstract}
Resumo: O artigo objetiva problematizar os movimentos de pesquisar experimentados pelo pesquisador no processo investigativo e seus efeitos criados na/pela estética e sensibilidades. Nossa reflexão baseia-se em: como a experiência estética e as sensibilidades podem afetar a pesquisa nos movimentos investigativos e seus desdobramentos na educação? Sobre essa indagação, dialogamos com alguns autores: Deleuze (2006, 1988 e 1974) Deleuze e Guatarri (1995 e 1992), trazendo o conceito de cartografia, nos possibilitando criar outros modos de pesquisar; Schiller (2017), com o conceito dos impulsos - sensível e formal, provocando a necessidade da articulação entre ambos, e a natureza ambígua da racionalidade e da subjetividade. Morin (2003 e 1999), abordando o pensamento complexo na educação, capaz de unir e contextualizar, sem perder de vista a singularidade; Meira e Pillotto (2010), ao mencionarem a experiência estética para pensar os processos educativos, como alimento que mobiliza e amplia as relações do sujeito no limiar do racional e do sensível; Maffesoli (2010, 2004 e 1998), que defende a razão sensível como uma alavanca metodológica para o exercício do pensamento. Para além desses autores, outros nos subsidiaram para a compreensão das sensibilidades como forças vitais e potência criadora que movem a existência humana e a pesquisa. Esse artigo, portanto, se constituiu no diálogo com as experiências em um Núcleo de Pesquisa em Arte na Educação, no qual pesquisar e pesquisar-se (entre)laçam-se com a estética e as sensibilidades. Ou seja, mapas vão se formando, se findando e se desdobrando nos processos educativos.
\end{abstract}

Palavras Chave: Educação. Experiência estética. Pesquisa. Sensibilidades.

\begin{abstract}
The article aims to problematize the research movements experienced by the researcher in the investigative process and their effects created in / by aesthetics and sensitivities. Our reflection is based on: how can aesthetic experience and sensitivities affect research in investigative movements and its consequences in education? About this question, we spoke with some authors: Deleuze (2006, 1988 and 1974) Deleuze and Guatarri (1995 and 1992), bringing the concept of cartography, enabling us to create other ways of research; Schiller (2017), with the concept of impulses - sensitive and formal, provoking the need for articulation between both, and the ambiguous nature of rationality and subjectivity. Morin (2003 and 1999), addressing complex thinking in education, able to unite and contextualize, without losing sight of the singularity; Meira and Pillotto (2010), when mentioning the aesthetic experience to think about educational processes, as a food that mobilizes and expands the subject's relationships at the threshold of the rational and the sensitive; Maffesoli (2010, 2004 and 1998), who defends sensitive reason as a methodological lever for the exercise of thought. In addition to these authors, others subsidized us to understand sensibilities as vital forces and creative power that drive human existence and research. This article, therefore, constituted a dialogue with the experiences in a Research Center for Art in Education, in which research and research (between) are linked with aesthetics and sensitivities. In other words, maps are being formed, ending and unfolding in the educational processes.
\end{abstract}

Key-words: Education. Aesthetic experience. Search. Sensitivities.

\section{Para citar - (ABNT NBR 6023:2018)}

PILLOTTO, Silvia Sell Duarte; SILVA, Carla Clauber da. Pesquisar e pesquisar-se na educação: movimentos criados pela estética e pelas sensibilidades. Eccos - Revista Cientifica, São Paulo, n. 53, p. 1-15, e16664, abr./jun. 2020. Disponível em: https://doi.org/10.5585/eccos.n53.16664. 


\section{Introdução}

$\mathrm{O}$ artigo aqui apresentado, tem como intenção pensar os movimentos de pesquisa vividos pelos pesquisadores, para identificar pistas dos seus efeitos criados pelas sensibilidades. A partir desse pressuposto, há que nos perguntarmos: como a experiência estética e as sensibilidades podem afetar a pesquisa, seus pesquisadores e interlocutores nos movimentos investigativos e seus desdobramentos na educação?

A abordagem de pesquisa está fundamentada pelo viés narrativo, trazendo nossas experiências com e nas pesquisas, oriundas do Núcleo de Pesquisa em Arte na Educação (NUPAE) e vinculado na Universidade da Região de Joinville (Univille), situada em Joinville, Santa Catarina.

No intuito de iniciarmos nossas narrativas sobre a temática aqui apresentada, é importante que sinalizemos os itens que serão destaques nos percursos desse artigo.

O item: Processos de Pesquisa: percursos e atravessamentos, abordará a criação de um Núcleo de Pesquisa em uma universidade que (entre)laça educação, arte e estética em movimentos de atravessamentos entre pesquisa e extensão. A educação é aqui entendida como campo complexo, que exige um caminhar incessante atravessado por um ir e vir, constituído de subjetividades, desejos e afectos.

Na sequência, Pesquisar-se: percursos formativos de sensibilidades, pretendemos dar visibilidade para o processo formativo do pesquisador durante seu percurso investigativo. Compreendemos aqui, a pesquisa como travessia e abertura para outras temporalidades, que envolvem o pensar, olhar, experimentar, estudar, investigar, compartilhar e narrar. Neste lugar está a cartografia, que mobiliza o pesquisador a viver seus campos de pesquisa, nos quais cria simultaneamente novos sentidos às suas experiências de vida.

Em Experiência Estética e Sensibilidades, o destaque fica por conta dos pressupostos teóricos/metodológicos que dão sustentação às pesquisas, ações e produções do Núcleo de Pesquisa em Arte na Educação - NUPAE, que trazem à luz dos conceitos a experiência estética e as sensibilidades. A escolha se deve, por entendermos que o estético impulsiona o olhar de si e do outro, mobilizando processos cognitivos e sensíveis, que ora se apresentam comuns ao grupo e ora são singulares. Nesse âmbito, as sensibilidades ganham força, ampliando a realidade dos pesquisadores e dos seus objetos de pesquisa, que no processo de compartilhamento desenham novos modos de pensar, sentir e experienciar a pesquisa.

Na sequência: Pesquisas (Entre)laçadas: Cartografando Experiências Estéticas, narramos a produção de três pesquisadoras integrantes do NUPAE, que em suas distintas áreas 
de formação - música, dança e artes visuais - desenvolveram suas pesquisas que se (entre)laçaram durante o percurso de investigação. Ainda nesse item, reiteramos a abordagem cartográfica, que possibilitou a conexão entre espaços, pesquisadores, interlocutores com as linguagens/expressões e ainda com a experiência estética e sensibilidades.

\section{Processos de pesquisa: percursos e atravessamentos}

Criar um núcleo de pesquisa em uma Universidade é uma ação que envolve, antes de tudo, a relação de corpos sensíveis, na qual se busca pela experiência conhecer-se e conhecer o outro. O Núcleo de Pesquisa em Arte na Educação nasceu com um caráter singular, mobilizado pelo desejo que afetou a nós professores para o (entre)laçar a educação e a pesquisa com a experiência estética. Um encontro de professores/pesquisadores que traziam em seus repertórios, ideias, experiências, sensibilidades e, especialmente, inquietações que emergiam nos diferentes espaços educacionais.

Na época da criação do Núcleo de Pesquisa, em 2003, a formação continuada ganhava novos contornos na área da educação - o professor tornava-se o protagonista do processo educativo. Assim, nosso envolvimento com a ação extensionista nos impulsionou para o desenvolvimento de projetos de formação, em especial para professores da Educação Básica das redes públicas do município de Joinville e região.

A aproximação com a formação de professores, abria uma escuta sensível para as problematizações advindas das práticas pedagógicas, principalmente para o campo da educação e do conhecimento, que é "[...] com efeito, uma navegação num oceano de incerteza respingado de arquipélagos de certeza" (MORIN, 1999, p.46). Os campos da educação e do conhecimento nos fizeram pensar outras possibilidades de encontros formativos, e novas composições advindas de curiosidades, de inquietações, de percepções, levando o grupo a percorrer processos investigativos, deslocando-nos para a pesquisa.

Os integrantes do núcleo de pesquisa reconhecem a complexidade presente na conexão entre pesquisa e extensão, entre ser professor e pesquisador, entre a arte, a estética e a educação. Na medida em que o uno se torna múltiplo, compreendemos que a complexidade

[...] é efetivamente a rede de eventos, ações, interações, retroações, determinações, acasos que constituem nosso mundo fenomênico. A complexidade apresenta-se, assim, sob o aspecto perturbador da perplexidade, da desordem, da ambiguidade, da incerteza [...] (MORIN, 2003, p.37-44).

Algo acontecia: eram mudanças que nos desestabilizavam em movimentos de improvisações, corpos impregnados de subjetividades, corpo-lugar de encontros com o outro e 
consigo mesmo. Linhas de tensões que se conectavam atravessando níveis de realidade, rompendo fronteiras entre a extensão e a pesquisa.

Isso porque, o processo de extensão na formação continuada de professores, de certa forma, limitava-nos ao exercício da reflexão, da escuta, da leitura e da escrita. Experimentávamos uma dicotomia entre o prescrito e o narrativo, entre o ensinar e o aprender, entre o processo e o produto, entre o dever e o desejo, entre o conhecido e o desconhecido, porque o tempo da ação extensionista é diferente do tempo da pesquisa que acontece no instante, como aborda Maldonato (2012, p. 16-17)

Todo instante é criação ato inaugural do existir. Mas o instante não é do tempo, é no tempo. Aliás o próprio instante é o tempo, o absolutamente único e imprevisível, presente que ressoa com outros instantes. Cada ato nosso de consciência está mergulhado no instante, em um agora que quebra a indiferente continuidade daquilo que é conhecido.

Desta forma, a pesquisa ganhou espaço, alimentada e conectada pelas inquietações advindas da extensão, corroborando para o Núcleo de Pesquisa, que desde o seu início teve a educação como fio condutor, articulados à arte e à estética. Mas há ainda outros afectos, que ampliaram as produções do Núcleo: as linguagens artísticas e as sensibilidades.

Neste sentido, Deleuze e Guattari (1992, p. 213) reiteraram nossas escolhas quando explicam que afectos são forças presentes e não sentimentos, nas quais "[...] transbordam a força daqueles que são atravessados por eles. As sensações, perceptos e afectos, são seres que valem por si mesmos e excedem qualquer vivido".

A presença da arte e da estética no Núcleo de Pesquisa talvez se encontre na história de sua criação que, inicialmente, foi composto por um grupo de professores/pesquisadores predominantemente com formação em Arte/Educação, os quais atuavam na Educação Básica e Superior e, fortemente, na extensão. Era um grupo que desejava dar tempo e espaço para a criação de outros movimentos nos quais a razão não estivesse separada do sensível e da experiência.

Movimentos que, para Schiller (2017, p. 57-60), podem ser compreendidos como impulsos lúdicos que conectam o sensível e o formal. Ou seja, para o autor o impulso sensível está relacionado às sensações, ao sentir; o pesquisador deseja receber o objeto de pesquisa, que é a própria vida em movimento, pois enquanto “[...] não sente, ele nada mais é do que forma e capacidade vazia".

Porquanto, pesquisar para o Núcleo foi e é um exercício de sensibilidades no qual, os pesquisadores experimentam o mistério, o não saber, o fascínio e o espanto daquilo que ainda não compreendem, mas que reconhecem o objeto de pesquisa como algo sempre em vias de se 
fazer. É um devir que, para Deleuze (2006, p. 11), é “[...] sempre inacabado, sempre a fazer-se, que extravasa toda a matéria vivível ou vivida. É um processo, quer dizer, uma passagem de Vida que atravessa o vivível e o vivido".

Por outro lado, isso não significa que as pesquisas produzidas pelo Núcleo, abandonam os impulsos formais, uma vez que são por meio destes que fornecemos as leis e a possibilidade de libertar o pensamento. Ou, nas palavras de Schiller (2017, p. 60), o impulso formal “[...] parte da existência absoluta do homem e de sua natureza racional e está empenhado em pô-lo em liberdade, levar harmonia à multiplicidade dos fenômenos e afirmar sua pessoa em detrimento de toda alternância do estado".

Quando assumimos a presença dos impulsos sensíveis no Núcleo de Pesquisa, queremos restituir às pesquisas seu caráter enigmático e seu processo inventivo, os quais permitam aos pesquisadores experienciar uma permanente curiosidade enquanto pesquisam, ou nas palavras de Maldonato (2012, p. 102)

É o maravilhar-se pela existência das coisas, precisamente como uma criança que olha o mundo, a abrir o caminho do conhecimento e a fazer com que exclamemos "como tudo isso é extraordinário". É o mistério a fazer que olhemos além das coisas e interroguemos o mundo.

Nesta perspectiva podemos afirmar que, as pesquisas são acontecimentos e como afirma Deleuze (1974, p. 152): “[...] o acontecimento não é o que acontece (acidente), ele é no que acontece o puro expresso que nos dá sinal e nos espera", encarnado no pesquisador.

À medida que os professores/pesquisadores foram se deslocando da Extensão para a Pesquisa, a cartografia começou a ser experimentada nos processos investigativos. No início, de forma tímida, imbricada ainda a outras metodologias e, aos poucos, desprendendo-se delas, ao perceber a potência da cartografia para pensar as multiplicidades produzidas, e para mapear os movimentos de intensidade, de afetos, e de sensibilidades.

A cartografia é um método criado por Deleuze e Guattari (1995), compreendido como um dos princípios do rizoma, concebido como um sistema que é a própria expressão da multiplicidade, a qual produz diferentes conexões, que podem transformar-se em novas formas, permitindo pensar o conhecimento e o próprio mundo como multiplicidade.

O rizoma, portanto, possui a característica de conectar um ponto a qualquer outro, pois não se detém a nenhum ponto de origem; investe na experimentação ou nas palavras de Deleuze e Guattari (1995, p. 31), “[...] nada de avanço significativo que não se faça por bifurcação, encontro imprevisível, reavaliação do conjunto a partir de um ângulo inédito".

As pesquisas do Núcleo vêm se constituindo em linhas rizomáticas, em diálogo com o percurso de cada pesquisador, os quais produzem diferentes conexões que se expressam em 
afetamentos experimentados no processo investigativo. Um mapa vai se formando dando a ver a trajetória da pesquisa a partir das múltiplas conexões, uma vez que a "[...] cartografia como método de pesquisa é o traçado desse plano da experiência, acompanhando os efeitos (sobre o objeto, o pesquisador e a produção do conhecimento) do próprio percurso da investigação" (PASSOS; KASTRUP; ESCÓSSIA, 2014, p. 18).

Na cartografia não há como prescrever um caminho definitivo, pois os resultados são encontrados durante os percursos, nas intervenções e na construção da pesquisa pelo pesquisador. Nesta perspectiva, Passos; Kastrup e Escóssia (2014, p. 138) afirmam que:

[...] a ocupação de um território numa pesquisa não pode ser iniciada com um problema fechado, sabendo de antemão o que se busca. Tal posicionamento fecha o encontro com a alteridade do campo territorial, permitindo muitas vezes só encontrar o que já se sabia ou, o que é muito pior, não enxergando nada além dos seus conceitos e ideias fixas. Portanto, para o aprendiz-cartógrafo, o campo territorial não tem a identidade de suas certezas, mas a paixão de uma aventura.

O Núcleo assume, portanto, um princípio de acolher as múltiplas expressões de pensamentos; um encontro entre pesquisadores de diferentes áreas: filosofia, arquitetura, pedagogia, história, artes, design, direito, matemática, letras; com diferentes experiências no campo acadêmico: professores, estudantes, artistas, gestores, que circulam em espaços outros, formais e não formais da educação: museus, escolas, universidades, centros de reabilitação, centro de artes, entre outros, o que torna possível experimentar, questionar, sentir, ouvir e ultrapassar os limites da prescrição.

\section{Pesquisar-se: percursos formativos de sensibilidades}

A pesquisa para os pesquisadores que integram o NUPAE, é uma travessia, uma viagem, que se abre em tempos outros, com pausas para o pensar, olhar, experimentar, estudar, investigar, compartilhar e narrar.

Essa travessia acontece em encontros, nos quais o estudar, para além de subsidiar as práticas de pesquisa, criam tempos para experiências estéticas, que conversam com os conceitos teóricos, nos quais os pesquisadores cartografam seus próprios processos investigativos, a partir dos afetamentos que emergem $\mathrm{da} /$ na pesquisa.

Nessa perspectiva, o NUPAE entende a pesquisa como movimento coletivo, que se (entre)laça em singularidades, potencializando o pensar e o sentir. Esses movimentos acontecem na mediação com o outro; uma travessia do não-saber ao saber, do si para o outro e do outro para si. Ou seja, nas palavras de Maffesoli (1998, p. 11): “[...] um saber incorporado que nada é absoluto, que não há verdade geral, mas que todas as verdades parciais podem entrar 
em relação umas com as outras". Assim, o saber para os pesquisadores do NUPAE é também constituído de incertezas, inquietações, estranhamentos, de encontros com o imprevisível, o qual exige “[...] sair da malha, estreita e sólida, dos conceitos estabelecidos" (MAFFESOLI, 1998, p. 17).

Ainda nesta direção é possível destacar, a reflexão trazida por Maldonato (2012, p. 103), quando descreve o caminho do conhecimento, enquanto um percurso, que é potencializado pelo não-saber: "[...] aquela sensação de mistério e de assombro que nos leva a ficarmos curvados dias a fio investigando as sutis arquiteturas de um objeto ou a questionar um texto até o limite dos sentidos, da lógica, do nosso próprio pensamento".

Nessa travessia, os pesquisadores cultivam a paixão pelo conhecimento e pelo pesquisar, que se conectam à sua própria existência. "Sem uma emoção, um arrepio da inteligência, seria impensável qualquer criação, também para as inteligências científicas mais estruturadas" (MALDONATO, 2012, p. 105).

Nos encontros que acontecem no NUPAE, as experiências estéticas alimentam o percurso formativo dos pesquisadores e da própria pesquisa. Linguagens e expressões artísticas, como: música, literatura, cinema, cerâmica, dança, performance, contação de histórias, desenho/pintura, escultura, gravura, artesanias, entre outras, dialogam e atravessam o conhecimento científico, impulsionando formas outras de pensar e fazer pesquisa.

O trabalho do pensamento em transfigurar aquilo que se vê, que se sente, que se pressente. Ou, para usar a metáfora, ser um talhador de ideias. Fazer brilhar a ideia ao talhá-la, como se provoca faíscas quando se golpeia a pedra (MAFFESOLI, 2010, p. 45).

Pesquisar para o NUPAE é, antes de tudo, criação; deslocamentos que se abrem à multiplicidade; o pensar e o sentir, conectam-se com as dimensões da sensibilidade. Ou seja, “[...] fazer que nasça aquilo que ainda não existe (não há outra obra, todo o resto é arbitrário e enfeite). Pensar é criar, não há outra criação, mas criar é, antes de tudo, engendrar 'pensar' no pensamento" (DELEUZE, 1988, p. 243). Por isso, o pesquisador do NUPAE se orienta em um mapa aberto, incompleto e sujeito a (trans)formações. Ou, nas palavras de Deleuze e Guattari (1995), um mapa com múltiplas entradas, o que faz desse pesquisador um cartógrafo.

É pela cartografia que o pesquisador vive seus campos de pesquisa, produzindo simultaneamente novos sentidos e potencializando suas experiências de vida; está sempre no gerúndio. Para Rolnik (2006, p. 66) o cartógrafo/pesquisador é aquele que “[...] deixa o seu corpo vibrar em todas as frequências possíveis e fica inventando posições a partir das quais essas vibrações encontrem sons, canais de passagem, carona para a existencialização". É um aceitar a vida, numa entrega definitiva de corpo e alma. 
Para Deleuze e Guattari (1995, p. 76), pela cartografia também se é afetado. "Somos atravessados por linhas, meridianos, geodésicas, trópicos, fusos, que não seguem o mesmo ritmo e não têm a mesma natureza". As linhas vão formando nosso mapa, que se transformam criando intersecções umas nas outras (DELEUZE; GUATTARI, 1995). Ainda nessa direção, Rolnik (2006, p. 65) corrobora ao descrever o cartógrafo como:

[...] um verdadeiro antropófago: vive de expropriar, se apropriar, devorar e desovar, transvalorado. Está sempre buscando elementos/alimentos para compor suas cartografias. Este é o critério de suas escolhas: descobrir que matérias de expressão, misturadas a quais outras, que composições de linguagem favorecem a passagem das intensidades que percorrem seu corpo no encontro com os corpos que pretende entender.

O percurso do pesquisador/cartográfico constitui-se de afetamentos e intensidades, de percepções e sensibilidades, a partir da experiência com o próprio objeto de pesquisa, consigo mesmo e nas relações construídas. É uma performance carregada de subjetividades, em movimentos contínuos que produz novos conhecimentos, saberes e sentires, sempre nas dimensões da cognição e das sensibilidades.

Dessa forma, a experiência estética no NUPAE “[...] é um fator de discernimento sensível, processo cognitivo que ocorre simultaneamente com a percepção, a atenção, memória e imaginação" (Meira, 2014, p. 55). Em outras palavras, vale ser dito que a experiência estética para nós pesquisadores, integrantes do NUPAE vem ganhando materialidade nos modos de escrita e socialização compartilhada de produções científicas. Fica evidente nas produções dos pesquisadores a presença de singularidades na medida em que as pesquisas são apresentadas em diferentes gêneros. Ainda vale destacar, a importância do grupo no processo investigativo de cada um, nas inferências, nas escritas, nas socializações compartilhadas e na escuta coletiva.

Para o NUPAE, o pesquisar não é um ato solitário, pois estamos afetando e sendo afetados pelo grupo. As ideias de um atravessam a do outro e o que inicialmente parece definitivo, abre-se para as intervenções do grupo, modificando-se, e criando outras. Assim, o estar junto é imprescindível, pois o processo de pesquisar e produzir conhecimento, são carregados de sensibilidades e interesse comum com o outro, integrando não somente a dimensão racional, mas sobretudo, a dimensão afetiva e emocional.

\section{Experiência estética e sensibilidades}

A experiência estética está envolta de um mistério, entre o indizível e um outro lugar. Como afirma Deligny (2018, p. 85) em seu mais consciente devaneio, é preciso pensar que “[...] existe o lugar de dizer e o outro lugar, que não é de dizer e não tem grande coisa a ver com (o) 
dizer, fora o que o dizer vem efetivamente acrescentar ainda por cima, aproveitando-se da coincidência, o que já aparece como sendo representado".

É nessa perspectiva que o NUPAE vem desenvolvendo suas pesquisas, alimentando-se da experiência estética e das sensibilidades, que agregam potenciais imagéticos e criativos. É desta forma, que a produção científica se intensifica e as ações de extensão também ganham força.

Assim, tem sido uma constante ação dos pesquisadores, o estudo teórico/metodológico sobre experiência estética e sensibilidades, e seus desdobramentos, uma vez que os caminhos percorridos pelos pesquisadores ganham novos contornos e, já não é suficiente recorrer ao já sabido/conhecido; faz-se necessário aprender. E aqui, vale destacar que a aprendizagem que defendemos é aquela que acontece pelos estudos e pelos sentidos que, para Meira (2014, p. 53) “[...] depende de afinar o corpo para vibrar de modo qualitativo em relação aos eventos sociais".

O Ser, neste caso, não é só espírito, se o é, está encarnado, pois tem pêlo, pele, vísceras, poderes e limites que emanam de sua sensibilidade corpórea, movimentos sem limites de sua imaginação e funções mentais, e com grande potencial interativo (MEIRA; PILLOTTO, 2010).

Em nossos encontros, Schiller (2017, p. 98) tem nos possibilitado compreender os percursos das pesquisas e seus afetamentos, pois compreende que há uma “[...] disposição intermediária, nas quais, sensibilidade e razão são simultaneamente ativas e por isso mesmo suprimem mutuamente seu poder de determinação, alcançando uma negação mediante uma oposição". Isso acontece porque a sensibilidade não exige a participação do sujeito e está para além da vontade e do conhecimento (SCHILLER, 2017).

O NUPAE tem articulado em suas ações, tanto de pesquisa quanto de extensão o conhecimento na sua dimensão sensível, pois compreendemos que o pensamento se manifesta pelos sentidos e é afetado por uma necessidade que vem do exterior. Ou seja, nas palavras de Maffesoli (2017, p. 94): “[...] uma necessidade fora de nós determina nosso estado e nossa existência no tempo através da impressão sensível. Esta é inteiramente involuntária, recebemola passivamente segundo a maneira pela qual somos afetados".

Nesse sentido, o aprender para os pesquisadores tem sido uma aprendizagem estética, uma vez que o estético nos impulsiona a olhar a si e ao outro, pois “[...] não existe maneira de fazer racional ao homem sensível sem torná-lo estético (SCHILLER, 2017, p. 109).

Nessa mesma linha de pensamento, Meira (2014, p. 55) afirma, sobre a aprendizagem estética, que a mesma envolve "[...] discernimento sensível, processo cognitivo que ocorre simultaneamente com a percepção, atenção, memória e imaginação". No espaço/tempo do NUPAE, a experiência estética é mobilizada pelo próprio grupo com graus de interesse ora 
comuns, ora singulares, e acima de tudo caracterizado por acontecimentos. Isto é possível por conta da experiência que “[...] desperta em cada um de nós protótipos mentais concretos e que variam em termos de ordem e desordem que se ligam à nossa história pessoal, ao nosso nível de escolarização, à cultura que tivemos em casa, na rua, no trabalho" (MEIRA, 2014, p. 57).

Essa não é uma tarefa fácil, em especial para os pesquisadores que iniciam no NUPAE, os quais expressam um pensamento linear e definitivo sobre seus respectivos objetos de pesquisa, colocando-se a parte do processo investigativo. Isso significa uma percepção de pesquisa sobre e para o outro, distanciando-o da pesquisa/vida.

Porém, no decorrer das experiências estéticas, os pesquisadores do NUPAE, cada um a seu tempo, vão rompendo gradativamente suas certezas. Para Maffesoli (1998, p. 19), esse exercício pressupõe pôr em prática uma "[...] deontologia que saiba reconhecer em cada situação a ambivalência que a compõe: a sombra e a luz entremeada, assim como o corpo e o espírito interpenetram-se como em uma organicidade fecunda". Pela experiência estética e pelas sensibilidades, é possível incorporar um saber capaz de integrar o caos, que saiba "[...] por mais paradoxal que isso possa parecer estabelecer a topografia da incerteza e do imprevisível, da desordem e da efervescência, do trágico e do não-racional. Coisas incontroláveis, imprevisíveis, mas não menos humanas" (MAFFESOLI, 1998, p. 13).

Esse movimento é a chave que se abre para todas as circunstâncias que nos aguardam, nas quais os imprevistos e as surpresas são nosso alimento estético. É uma experiência descrita por Deligny (2018, p. 119) como um:

Profundamente adormecido, "eu" surge, desperto, mas "eu" se aflige ao se sentir em um corpo imóvel, inerte, mineral. Então, "eu" busca os contatos, as alavancas. "Eu" busca o mais sensível, o mais leve, um dedinho, os lábios, as pálpebras e, com todas as suas forças dirigidas a um desses pontos, "eu" consegue uma onda, um estremecimento, um movimento leve e quase imperceptível, que é como um imenso alívio, pois ele basta para me impelir ao movimento reencontrado e ao mundo vivo que me aguarda.

As sensibilidades, nesse âmbito ampliam a realidade, tanto do pesquisador, quanto de seu próprio objeto de pesquisa, que se tornam plurais, polissêmicos e complexos. Uma integração de si com o grupo; uma relação de compartilhamento de ideias, afetos e emoções, que atravessam o processo investigativo (MAFFESOLI, 2004).

Nessa trajetória, destacamos a produção de três pesquisas desenvolvidas no NUPAE, que no movimento da experiência estética se (entre)laçaram numa comunhão de pensamentos e sensibilidades. 


\section{Pesquisas (entre)laçadas: cartografando experiências estéticas}

Quando se pensa a pesquisa conectada entre pesquisadores e interlocutores, entende-se que os processos investigativos agregam os interlocutores também como autores, pois são partícipes na trajetória de pesquisar. Essa é uma escolha do NUPAE, que compreende a pesquisa e a extensão como possibilidade de compartilhamento de ideias e experiências.

A pesquisa é sempre uma escolha conectada aos pesquisadores e seus interlocutores. Há algum tempo esse tem sido o lema do NUPAE. E mais do que isso, pensar em possibilidades de pesquisas (entre)laçadas que permeiam caminhos comuns e singulares entre pesquisadores e coautores da pesquisa.

Os percursos, que envolvem a experiência estética, as sensibilidades, as artes e a educação intercruzam-se no ensinar e no aprender, nos quais o saber emerge durante o processo de fazer/pensar a pesquisa.

Assim, destacamos a produção de três pesquisadoras do NUPAE, que em suas distintas áreas de formação - música, dança e artes visuais - desenvolveram suas pesquisas que se (entre)laçaram durante o processo de investigação. Em comum entre as pesquisas foram os espaços (educação infantil da rede pública e museu), os interlocutores (20 crianças entre 4 e 5 anos) e a abordagem metodológica - cartografia.

Os objetos de pesquisa estiveram articulados à área de formação de cada uma delas, o que produziu múltiplas entradas, configurando-se em um mapa móvel, deslocando as pesquisadoras entre saberes e sentires. Nesse processo, emergiam pistas, guiando suas travessias. (PASSOS; KASTRUP; ESCÓSSIA, 2015).

A pesquisa: Mediação cultural por meio da dançaleducação como possibilidade de aprendizagem na infância, teve como foco a interação e experiência corpóreo/sensível. A outra: Vivências perceptivas com a infância nos espaços da escola e do museu - uma experiência, abordou ações de mediação cultural nos espaços escolhidos e seus afetamentos nos aspectos sensíveis das crianças. E por fim, a pesquisa: Uma cartografia com a infância: experiências e múltiplas sonoridades, destacou práticas de mediação/interlocução com experiências sonoras na infância.

As linguagens/expressões trataram do corpo/movimento, do desenho e modelagem e da musicalização. As crianças, interlocutoras/coautoras das três pesquisas, movimentavam-se, (entre)laçando-se: ao dançar, histórias eram narradas em dó maior; enquanto desenhavam, ritmos sonoros acompanhavam o movimento corporal; quando cantavam, seus corpos vibravam 
em cores mil. Além disso, a escuta ganhou potência na voz das crianças e na percepção dos ambientes (cultural e natural), entre tantos outros.

Portanto, pesquisas (entre)laçadas foram constituídas de experiências estéticas, sensibilidades e pistas, as quais foram se delineando durante o percurso investigativo. Isso implicou na interação entre os pesquisadores com as crianças, na ampliação de saberes e conhecimentos e no rompimento entre fronteiras das linguagens e expressões. Assim, as pesquisadoras foram se reinventando como cartógrafas, aproximando-se do campo de pesquisa como estrangeiras de um território ainda não habitado, mas que foi explorado por olhares, escutas, corporeidade, ou seja, pelas sensibilidades (PASSOS; KASTRUP; ESCÓSSIA, 2015).

As três pesquisas buscaram superar a linearidade do pensamento por meio do diálogo e das interações; e ao movimentarem-se por diferentes territórios, experimentaram situações de imprevisibilidade, produzindo diferentes sentidos e novos modos de fazer pesquisa.

Nessa trajetória de pensar/fazer/sentir a pesquisa, estamos imprimindo também quem somos. Para Meira; Pillotto (2010, p. 82): “[...] através do sensível pode-se perguntar de que modo somos afetados por aquilo que interfere em nosso estilo de ser, por aquilo que nos encanta ou desencanta, pelo o que ainda surpreende ou não mais”.

Esse movimento foi possível pela abordagem cartográfica, a qual compreende a experiência como essencial nos processos perceptivos do que é observado e vivido. A intenção aqui foi a de nos deslocarmos " [...] de pontos de vista que tomam a metodologia como conjunto de normas absolutas, prescrições técnicas e procedimentos imperativos; não falamos de regras fixas” (PASSOS; KASTRUP; TEDESCO, 2014, p. 9).

Ainda nessa direção, Deleuze e Guattari (1995, p. 33) destacam a transversalidade, própria de uma pesquisa cartográfica e que perpassa pelo rizoma, o qual os autores entendem como caminho que:

[...] não começa nem conclui, ele se encontra sempre no meio, entre as coisas, interser, intermezzo. A árvore é filiação, mas o rizoma é aliança, unicamente aliança. A árvore impõe o verbo ser, mas o rizoma tem como tecido a conjunção "e...e...e". Há nessa conjunção força suficiente para sacudir e desenraizar o ver ser.

Assim, as referidas pesquisas contribuíram com reflexões para o âmbito da educação, em especial para uma educação que prima pela experiência estética e pelas sensibilidades. Morin (1999) deixa claro a importância de uma educação humanitária em prol da vida e da diversidade humana. Para o autor, essa é uma educação que fortalece o caráter poético da vida.

Nessa perspectiva, é possível dizer que as três pesquisas (entre)laçadas e no viés cartográfico, potencializaram o diálogo, a escuta, a experiência estética e as sensibilidades, o 
que mobilizou os processos de criação, e instaurou novas formas de olhar das crianças e pesquisadoras.

\section{6 (In)conclusões}

Ao propormos problematizar os movimentos de pesquisar experimentados pelo pesquisador no processo investigativo e seus efeitos criados na/pela estética e sensibilidades, nosso fio condutor foi a experiência estética e as sensibilidades, a partir do NUPAE.

O referido Núcleo, compreende que o processo de pesquisar e pesquisar-se podem (entre)laçar-se com a experiência estética e as sensibilidades, restituindo às pesquisas seu caráter enigmático e seu processo inventivo.

As pesquisas se formam em linhas rizomáticas, produzindo diferentes conexões que se apresentam em afetamentos, experimentados pelo pesquisador durante seu processo de pensar/fazer e reinventar modos de pesquisar. Da mesma forma, acontecem nas experiências com a formação (seja na extensão ou no ensino), entendida por nós como um diálogo “[...] com as práticas pedagógicas e com os sujeitos em suas subjetividades" (SILVA; PILLOTTO; LEAL, 2017, p. 201). E também na apropriação de metodologias que provoquem o pensar, a criação e a liberdade, e que se alimentam da estética e das sensibilidades. A ética como uma atitude, que define estar só e estar com o outro. E a estética como reflexão de quem somos para nós e para o outro.

As experiências estéticas e as sensibilidades, atravessam o conhecimento científico, alimentando o percurso formativo dos pesquisadores e da própria pesquisa, fomentadas pelas linguagens e expressões artísticas. Experiências que visam à constituição do sujeito "[...] como ser livre, que traz em sua prática uma ética do eu que se confronta na relação consigo próprio e que está voltada ao modo de conduzir a própria vida, a existência, negando projeções de como o sujeito deve ser na sociedade" (SILVA; PILLOTTO; LEAL, 2017, p. 189).

A partir de movimentos libertadores do pensamento e dos sentires, os integrantes do NUPAE têm compreendido que o pesquisar não é um ato solitário, pois afetamos e somos afetados; nada é definitivo, uma vez que o pensamento de cada pesquisador se abre para a escuta numa dimensão cognitiva, afetiva e emocional. Nesse sentido, as sensibilidades ampliam a realidade do pesquisador, tornando-se plurais, polissêmicas e complexas.

Diferentes olhares podem trazer conhecimentos, assim como diferentes escutas se houver sensibilidade que permita a atenção, o envolvimento, o tempo necessário para romper com impedimentos de ordem material e mental. Complementando esses elementos é também 
incorporada a essa multiplicidade, a leitura, o debate, e a análise teórica, sobretudo, como uma prática criadora (MEIRA; PILLOTTO, 2010).

A experiência estética e as sensibilidades têm afetado nossa percepção no que diz respeitos relações entre a pesquisa e a extensão, fortalecendo o caráter poético e humanitário numa educação pela vida.

\section{Referências}

DELEUZE, Gilles. El Leibniz de Deleuze: exasperación de la filosofia - $1^{\text {a }}$ ed. - Buenos Aires: Cactus, 2006.

DELEUZE, Gilles. Lógica do sentido. Tradução de Luiz Roberto Salinas Fortes. São Paulo: Perspectiva, Editora da Universidade de São Paulo, 1974. (Estudos 35)

DELEUZE, Gilles. Diferença e Repetição. Tradução: Luis Orlandi, Roberto Machado. Rio de Janeiro: Graal, 1988.

DELEUZE, Gilles.; GUATTARI, Felix. O que é a Filosofia? Trad. Bento Prado Jr. e Alberto Alonso Muñoz. São Paulo: Editora 34, 1992.

DELEUZE, Gilles.; GUATTARI, Felix. Mil Platôs: capitalismo e esquizofrenia. Vol. I. São Paulo: Ed.34, 1995.

DELIGNY, Fernand. Os vagabundos eficazes, operários, artistas, revolucionários: educadores. Tradução e notas: Marlon Miguel. São Paulo. N- Edições, 2018.

MAFFESOLI, Michel. Saturação. Tradução: Ana Goldberger. São Paulo. Iluminuras: Itaú Cultural, 2010.

MAFFESOLI, Michel. Elogio da razão sensível. Tradução: Albert Christophe Migueis Stuckembruck. Petrópolis, RJ: Vozes, 1998.

MAFFESOLI, Michel. A Parte do Diabo. Rio de Janeiro: Record, 2004.

MALDONATO, Mauro. Passagens do tempo. São Paulo: Edições SESC São Paulo, 2012.

MEIRA, Marly. O sentido de aprender pelos sentidos. In: PILLOTTO, Silvia S. D; BOHN, Letícia R D. Arte/Educação: ensinar e aprender no ensino básico. Joinville, SC: Editora: UNIVILLE, 2014.

MEIRA, Marly; PILLOTTO, Silvia Sell Duarte. Arte, afeto e educação: a sensibilidade na ação pedagógica. Porto Alegre: Mediação, 2010.

MORIN, Edgar. Complexidade e transdisciplinaridade: a reforma da universidade e do Ensino Fundamental. Natal: Editora da UFRN, 1999. 
MORIN, Edgar. Educar na era planetária: o pensamento complexo como método de aprendizagem pelo erro e incerteza humana. São Paulo: Cortez; Brasília, DF: UNESCO, 2003 PASSOS, Eduardo; KASTRUP, Virgínia; ESCÓSSIA, Liliana da (orgs.). Pistas do método da cartografia: pesquisa-intervenção e produção de subjetividade. Porto Alegre: Sulina, 2014.

ROLNIK, S. Cartografia sentimental: transformações contemporâneas do desejo. Porto Alegre: Editora da Universidade Federal do Rio Grande do Sul, 2006.

SCHILLER, Friedrith. A educação estética do homem. Trad. Roberto Schwarz e Marcio Suzuki. São Paulo. Iluminuras, 1989. (reimpressão 2017)

SILVA, Carla Clauber da; PILLOTTO, Silvia Sell Duarte; LEAL, Patrícia Regina Carvalho. Formação: uma experiência estética carregada de fragilidades de vida Nuances: Estudos sobre Educação. Presidente Prudente-SP, v. 28, n. 3, p. 186-205, Set/Dez, 2017. 